\title{
Effect of tumour-cell-derived or recombinant keratinocyte growth factor (KGF) on proliferation and radioresponse of human epithelial tumour cells (HNSCC) and normal keratinocytes in vitro
}

\author{
Andrea Hille · Susanne Grüger · Hans Christiansen · \\ Hendrik A. Wolff · Beate Volkmer · Jörg Lehmann • \\ Wolfgang Dörr $\cdot$ Margret Rave-Fränk
}

Received: 27 November 2009 / Accepted: 5 February 2010 / Published online: 7 March 2010

(c) The Author(s) 2010. This article is published with open access at Springerlink.com

\begin{abstract}
Purpose of this work was to test the effect of tumour-cell-derived keratinocyte growth factor (KGF) or recombinant $\mathrm{KGF}$ (palifermin) on cell proliferation and radiation response of human HNSCC cells and normal keratinocytes in vitro. Four tumour cell cultures derived from head and neck squamous cell carcinomas, primary keratinocytes, and immortalized keratinocytes were analysed. Fibroblasts, the natural source of KGF protein, served as controls. KGF expression was observed in primary and immortalized keratinocytes, fibroblasts, and in tumour cells, while significant KGF receptor expression was only found in keratinocytes. Recombinant KGF as well as tumour-cell-derived KGF caused a significant growth stimulation and radioprotection in keratinocytes, which was abolished by a neutralizing anti-KGF antibody. This indicates that tumour-cell-derived KGF is biologically active. In the tumour cell lines, no significant growth stimulation was induced by recombinant KGF, and the neutralizing
\end{abstract}

A. Hille $\cdot$ S. Grüger $\cdot$ H. Christiansen $\cdot$ H. A. Wolff .

M. Rave-Fränk ( $\square)$

Department of Radiotherapy and Radiooncology,

University Medicine Göttingen, Göttingen, Germany

e-mail:mfraenk@med.uni-goettingen.de

B. Volkmer

Dermatology Centre Elbeklinikum Buxtehude,

Buxtehude, Germany

J. Lehmann

Department of Radiation Oncology,

University of California Davis School of Medicine,

Sacramento, CA, USA

W. Dörr

Department of Radiotherapy and Radiation Oncology, Medical Faculty Carl Gustav Carus, University of Technology,

Dresden, Germany antibody did not influence tumour cell growth or radiation response. Our results indicate that the normal, paracrine KGF regulatory mechanisms, which are based on KGF receptor expression, are lost in malignant cells, with the consequence of irresponsiveness of the tumour cells to exogenous KGF. In face of the amelioration of the radiation response of normal epithelia, demonstrated in various clinical and various preclinical animal studies, recombinant KGF represents a candidate for the selective protection of normal epithelia during radio(chemo) therapy of squamous cell carcinoma.

\section{Introduction}

Oropharyngeal mucositis is a frequent and dose-limiting early side effect in radiotherapy of head and neck cancer. Severe mucositis causes nutritional insufficiency, pain, and susceptibility to infection, which affect patients' compliance to the treatment. It often necessitates interruption or cessation of the prescribed therapy, with the consequence of a substantial decrease in local control probability. Amelioration of the mucosal response, aiming at avoiding therapy interruptions, could thus increase the therapeutic ratio of radiotherapy of head and neck malignancies. A large variety of strategies have been tested for this purpose in recent years, both in patients and in animal models (Dorr 2003; Epstein and Klasser 2006; Keefe et al. 2007). However, apart from improvement of oral hygiene, adequate pain medication and antibiotic/antimycotic treatment, none of these approaches has so far been established in clinical routine, indicating their relative ineffectiveness.

Keratinocyte growth factor [KGF; also termed fibroblast growth factor 7 (FGF7)] is predominantly produced by cells of mesenchymal origin and acts exclusively through a 
specific KGF receptor [fibroblast growth factor receptor (FGFR2b)], which is expressed primarily by epithelial cells. KGF regulates epithelial proliferation, differentiation, and migration and has an important role in epithelial wound repair. This growth factor hence represents a paracrine mesenchymal-epithelial mediator. A truncated recombinant form of human KGF ( $\Delta 23-\mathrm{rHuKGF}$, palifermin) has been shown to significantly ameliorate the acute radiation response of various epithelial tissues (mouse tongue, intestine, salivary glands, airways, urinary bladder) in animal models (Danilenko 1999; Dorr et al. 2002a, b, c; Dorr et al. 2005b, c; Dorr et al. 2001; Farrell et al. 1998, 1999; Fleischer and Dorr 2006; Jaal and Dorr 2007; Khan et al. 1997; Kilic et al. 2007; Lombaert et al. 2008; Okunieff et al. 2001). More important, this protective efficacy of recombinant KGF for normal epithelial tissues has been confirmed in combination with conditioning treatment for progenitor cell transplantation for haematological malignancies (Spielberger et al. 2004) as well as for radio(chemo) therapy for head-and-neck tumours in first clinical studies (Brizel et al. 2008; Meropol et al. 2003). The detailed mechanisms, through which KGF exerts the protective effect, currently remain unclear.

One major concern with respect to the clinical use of recombinant $\mathrm{KGF}$ in combination with the treatment of solid epithelial malignancies is that the agent may not only protect normal epithelia but also the tumour. Most of the studies which tested the effect of recombinant KGF on tumour cell survival after treatment with anticancer drugs or radiation did not demonstrate any substantial protective activity. Similarly, no significant effect of recombinant KGF was demonstrated in animal tumour models; yet these studies used tumour growth delay rather than tumour cure as the endpoint [reviewed in (Dorr 2003)]. However, some experiments suggested that recombinant KGF might have antiapoptotic activity [reviewed (Finch and Rubin 2006)].

We showed previously that the addition of recombinant KGF to the medium of early passage HNSCC and lung tumour cell cultures does not affect radiation-induced impairment of proliferation nor clonogenic cell survival (Hille et al. 2003). These tumour cells expressed KGF mRNA and protein, and low levels of KGF receptor mRNA. One plausible explanation for the lacking effect of KGF was the very low level of KGF receptor mRNA expression in the tumour cells. Moreover, the endogenous KGF expression by the tumour cells may render them independent of exogenous KGF signalling, thus suggesting replacement of the normal paracrine with an autocrine mechanism in case of malignant growth.

Whether this KGF expressed in tumour cells is biologically active, remains unclear. Therefore, the aim of the present study was to evaluate the effect of recombinant KGF and tumour-cell-derived KGF on cell proliferation and radiation response in human epithelial tumour cells and normal keratinocytes in vitro.

\section{Materials and methods}

\section{Cell culture}

All cells were cultured at $37^{\circ} \mathrm{C}$ in a $5 \% \mathrm{CO}_{2}$ atmosphere. Three tumour cell lines, ZMK-1, BW-255, and GR-145, were derived from human squamous cell carcinomas of the oropharynx, one cell line, OH-65, was derived from the hypopharynx. At least $500 \mathrm{mg}$ of tumour material were disaggregated and cultured in complex medium consisting of Dulbecco's minimal essential medium (DMEM) and Ham's F12 (50:50), 15\% foetal calf serum (FCS), $0.5 \mu \mathrm{g} /$ $\mathrm{ml}$ hydrocortisone, $2 \mathrm{ng} / \mathrm{ml}$ epidermal growth factor, $5 \mu \mathrm{g} /$ $\mathrm{ml}$ insulin, antibiotics, and fungizone. For tumour cell culture, a viable cell count was obtained by trypan blue exclusion. In culture flasks, 100,000 cells/ml medium were placed, with twice weekly change of medium and grown to confluence. Cell stocks were stored in liquid nitrogen in their 1st to 3rd passage.

Primary keratinocytes were isolated from skin biopsies obtained during dermatological surgery. Fat and connective tissue was removed, and the skin biopsy was dissected into $0.5-\mathrm{cm}^{2}$ pieces. The samples were washed in gentamycine $(0.2 \mu \mathrm{g} / \mathrm{ml})$ three times for $10 \mathrm{~min}$ and incubated in thermolysine $(0.5 \mathrm{mg} / \mathrm{ml})$ overnight at $4^{\circ} \mathrm{C}$. Then the epidermis was dispatched from the dermis and collected in $0.04 \%$ EDTA. An equal volume of preheated $0.1 \%$ trypsin/EDTA was added and the epidermis was incubated for $6 \mathrm{~min}$ at $37^{\circ} \mathrm{C}$. Within these $6 \mathrm{~min}$, the probe was shaken every $2 \mathrm{~min}$. The trypsin reaction was stopped by addition of an adequate volume of DMEM $/ 10 \%$ FCS. Cells were spun down $(200 \times \mathrm{g}, 10 \mathrm{~min})$ and resuspended in $1-2 \mathrm{ml}$ keratinocyte growth medium (Promocell GmbH, Heidelberg, Germany) consisting of Keratinocyte Basal Medium, 0.4\% Bovine Pituitary Extract, $0.125 \mathrm{ng} / \mathrm{ml}$ Epidermal Growth Factor, $5 \mu \mathrm{g} / \mathrm{ml}$ human Insulin, $0.33 \mu \mathrm{g} / \mathrm{ml}$ Hydrocortison, $10 \mu \mathrm{g} / \mathrm{ml}$ Transferrin, $0.39 \mu \mathrm{g} / \mathrm{ml}$ Epinephrine and $0.15 \mathrm{mM}$ $\mathrm{CaCl}$. Primary keratinocytes were used in their 2 nd to 4 th passage.

HaCat cells (immortalized keratinocytes), originally generated by Boukamp and Fusenig (Boukamp et al. 1988) were purchased through CLS Cell Line Services Eppelheim, Germany. They were cultured in medium consisting of DMEM and $10 \%$ FCS.

Primary fibroblasts, the natural source of KGF, were derived from a biopsy of a healthy male donor by outgrowth technique and used in their 3rd-5th passage. They were cultured in medium consisting of DMEM and $10 \%$ FCS. 
The use of tumour material and skin biopsies was approved by the ethical committee of the Medical Faculty of the Georg-August-Universität Göttingen (no. 6/6/96), and healthy volunteers and patients gave their informed consent.

Keratinocyte growth factor ( $\Delta 23-\mathrm{rHuKGF}$, Palifermin)

Amgen Inc., Thousand Oaks, CA, kindly supplied lyophilized recombinant KGF [truncated ( $\Delta 23$-rHuKGF (Palifermin)]. The recombinant human growth factor was produced in Escherichia coli, purified to homogeneity by conventional chromatography, and tested for the presence of endotoxin by the company. The lyophilizate was first dissolved in aqua ad injectabile and then further diluted in culture medium. The final solution was freshly prepared before each experiment, and final concentrations from $0.2-1 \mu \mathrm{g} / \mathrm{ml}$ were used.

\section{Irradiation}

Cells were irradiated with $200 \mathrm{kV}$ X-rays at a dose rate of $1.25 \mathrm{~Gy} / \mathrm{min}$. Radiation doses of 1 and $4 \mathrm{~Gy}$ were given as single doses. Cells were irradiated as suspension and plated for the respective experiments immediately after irradiation. Sham-irradiated cultures served as specific controls.

Determination of the amount of KGF in cell culture supernatants

The amount of KGF protein was determined in cell culture supernatants by the QuantikineTM Human KGF (FGF-7) Immunoassay (DKG00), R \& D Systems, Minneapolis, USA, according to recommended protocol. For experiments, tumour cells, keratinocytes, or fibroblasts $(100,000$ cells/well) were seeded on 12-well plates (Nalge Nunc Int., Rochester, NY) in their specific medium and allowed to attach for $24 \mathrm{~h}$. Thereafter, the medium was replaced by the KGF-free medium used for keratinocyte culture, and the cells were incubated for further $72 \mathrm{~h}$. For KGF measurement, supernatants were collected, and particulates were removed by centrifugation.

\section{Western blot}

The expression of KGF and KGF receptor in tumour cell lines, primary fibroblasts, primary keratinocytes, and HaCat cells was tested by Western Blot analysis. Cells grown to $80 \%$ confluence in $25-\mathrm{cm}^{2}$ culture flasks were washed with cold PBS and then scraped in a small volume of PBS. After lysis and whole protein content determination, proteins were separated by $10 \%$ SDS-PAGE and subsequently electrotransferred onto nitrocellulose membranes. For protein detection, the WesternBreeze Chromogenic Immunodetection System (Invitrogen, Carlsbad, USA) was used following the instructions of the manufacturer. Primary antibodies were for KGF MAB2511 Clone 29568, dilution 1:250; for KGF receptor MAB665 Clone 98707, dilution 1:250 (both R\&D Systems) and for actin IgG1, dilution 1:1,000 (Santa Cruz, Santa Cruz, USA). Incubation time for these antibodies was $90 \mathrm{~min}$.

\section{Real-time PCR}

Relative quantification of mRNA expression for $\mathrm{KGF}$ and KGF receptor was performed with SYBR Green PCR Master Mix (Eurogentec, Seraing, Belgium) using a thermal cycler ABI PRISM 7700 (Perkin-Elmer-Applied Biosynthesis, Foster City, CA). Total RNA was isolated from tumour cell lines, HaCat cells, and primary keratinocytes with the RNeasy Mini Kit (Qiagen) according to the manufacturer's instructions. Aliquots of $1 \mathrm{mg}$ of total RNA, random primers, and Moloney murine leukaemia virus reverse transcriptase (Invitrogen) were used for cDNA synthesis. The PCR was done with cDNA aliquots and primer sequences specific for human $\mathrm{KGF}$, KGF receptor, and $\beta$-actin. Primer sequences are available upon request. Relative quantification of target gene expression was calculated by the comparative threshold cycle $(\mathrm{Ct})$ method.

\section{CellTiterBlue viability test}

The CellTiterBlue viability assay from Promega (Promega Corporation, Madison, WI, USA), a method for estimating the number of viable cells present in a given cell population, was used according to the manufacturer's instructions. Cells were grown in 96-well tissue culture plates in $100 \mu \mathrm{l}$ culture medium, and cell viability was tested after 24,48 , 72 , and, $96 \mathrm{~h}$ at $37^{\circ} \mathrm{C}$. For this, cells were incubated with $20 \mu \mathrm{l}$ CellTiterBlue reagent for $3.5 \mathrm{~h}$, and results were recorded at $570 \mathrm{~nm}$ wavelength (reference $600 \mathrm{~nm}$ ) using a plate reader (GENIOS PLUS, Tecan Deutschland GmbH, Crailsheim, Germany). To test for stimulating effects of $\mathrm{KGF}$, cells were either plated in cell culture supernatants obtained as described under "Determination of the amount of KGF in cell culture supernatants" or in rHuKGF-containing medium at concentrations from 0.2 to $1 \mu \mathrm{g} / \mathrm{ml} \mathrm{rHu}$ KGF. For neutralization experiments, KGF antibody (MAB251 Clone 29522) at a concentration of $2 \mu \mathrm{g} / \mathrm{ml}$ was added to the cell culture medium (supernatants) $1 \mathrm{~h}$ before plating. This antibody concentration had previously been demonstrated to be sufficient for the neutralization of 15 $25 \mathrm{ng}$ KGF. Cell cultures treated with unspecific IgG antibodies served as respective controls. Experiments were performed in triplicate and repeated 3-4 times, and for analysis, data were normalized to the $24-\mathrm{h}$ records. 
Table 1 KGF concentrations measured in cell culture supernatants

\begin{tabular}{lc}
\hline Cell line & $\begin{array}{l}\text { Mean KGF concentration } \\
\text { after 72-h incubation } \\
(\mathrm{pg} / \mathrm{ml})\end{array}$ \\
\hline DF-19 & 23.7 \\
BW-225 & 95.5 \\
GR-145 & 9.8 \\
OH-65 & 23.0 \\
ZMK-1 & 329.0 \\
HaCat & 4.8 \\
\hline
\end{tabular}

Data analysis

Means and standard errors were calculated for each of the data points; statistical comparison was done using the $t$-test for each dose point. Statistical comparison was performed between cultures treated with rHuKGF, tumour-derived KGF and no KGF; cultures treated with or without antibody, and irradiated and non-irradiated cells. All analyses were performed with KaleidaGraph ${ }^{\mathrm{TM}}$ 3.5, Synergy Software, Reading PA, USA.

\section{Results}

Detection of KGF in supernatants of tumour cell lines and fibroblasts by ELISA

The secretion of KGF protein into the culture medium was tested for fibroblasts (DF-19), tumour cell cultures (BW225, GR-145, OH-65, ZMK-1), and immortalized keratinocytes (HaCat) by ELISA. All supernatants contained KGF, the highest KGF concentrations being found for ZMK-1 and BW-225 cells. Table 1 lists the measured concentrations.

Detection of KGF and KGF receptor in tumour cell lines, fibroblasts and keratinocytes by western blot and real-time PCR

Intracellular KGF was detected in fibroblasts (DF19), the tumour cell cultures (BW-225, GR-145, OH-65, ZMK-1), and primary and immortalized (HaCat) keratinocytes. A typical Western Blot is shown in Fig. 1a.

In contrast, KGF receptor, at the expected molecular weight, was only detected in keratinocytes. Some tumour cells showed bands at higher molecular weights, which might represent aberrant receptor forms or unspecific signals. An example is shown in Fig. 1b.

Real-time PCR was performed to test for radiationinduced changes in KGF and KGF receptor mRNA expression. In accordance with the western blot results, KGF mRNA expression was found in fibroblasts (DF-19), all tumour cell lines (BW-225, GR-145, OH-65, ZMK-1), and primary and immortalized (HaCat) keratinocytes. Primary keratinocytes (KTC) as well as HaCat cells showed increased KGF mRNA expression after irradiation at 6 and $24 \mathrm{~h}$, and at both radiation doses of 1 and $4 \mathrm{~Gy}$. KGF mRNA expression in fibroblasts was increased after $24 \mathrm{~h}$. In tumour cells, up- as well as down-regulation of KGF mRNA was detected. Figure 2a summarizes the results; the mRNA expression is normalized to the unirradiated controls.

In accordance with the Western Blot results, significant KGF receptor mRNA expression was only found in primary keratinocytes and $\mathrm{HaCat}$ cells. Figure $2 \mathrm{~b}$ shows that KGF recptor mRNA expression in primary keratinocytes is upregulated at both time points and radiation doses, while KGF receptor mRNA expression in HaCat cells is nearly unaffected by radiation.

Cell proliferation of keratinocytes in response to recombinant $\mathrm{KGF}$, cell-derived $\mathrm{KGF}$

and anti-KGF antibody treatment

Compared to the cell proliferation in KGF-free medium a significant increase in cell proliferation was observed for cells treated with $0.2,0.5$, and $1.0 \mu \mathrm{g} / \mathrm{ml}$ recombinant KGF. No significant difference in proliferation was found between the recombinant KGF concentrations. Figure 3a shows growth curves for keratinocytes incubated in medium containing 0.2 or $1.0 \mu \mathrm{g} / \mathrm{ml}$ recombinant KGF, respectively. Recombinant KGF-induced increased proliferation was also observed in keratinocytes irradiated at 1 or 4 Gy (Fig. 3b). This increased proliferation could be abrogated by the addition of a neutralizing anti-KGF antibody. Data were recorded at $24,48,72$, and $96 \mathrm{~h}$, and significant
Fig. 1 a Example of KGF expression in normal (keratinocytes, fibroblasts DF-19) and tumour (ZMK-1, GR-145, BW-225, OH-65) cells. b KGF receptor expression in keratinocytes and ZMK-1 tumour cells

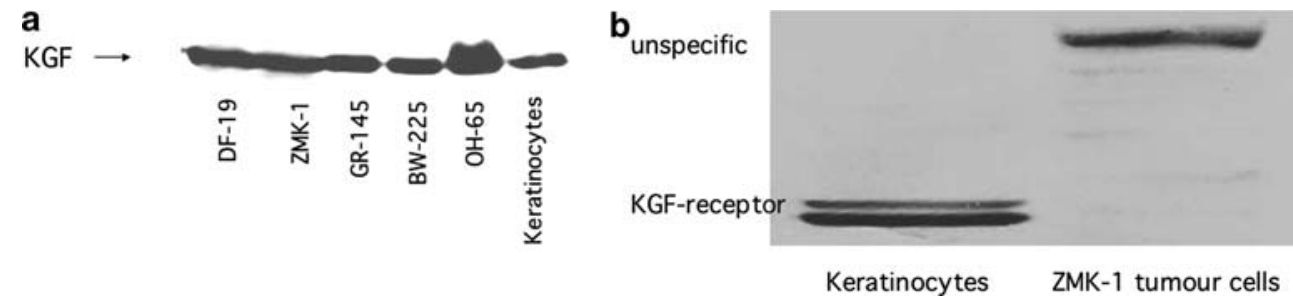




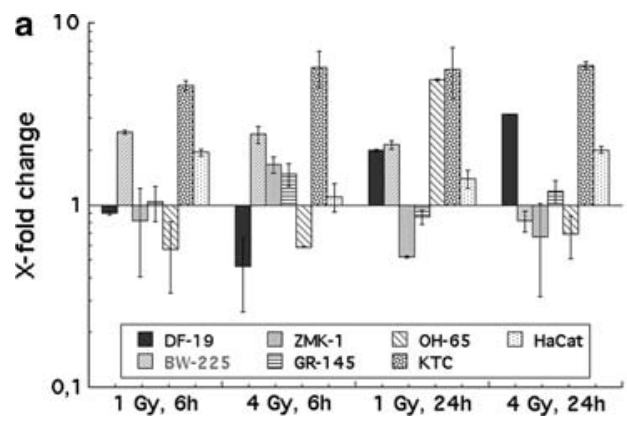

Fig. 2 a Radiation-induced changes in KGF expression in normal $(\mathrm{KTC}=$ primary keratinocytes, HaCat $=$ immortalized keratinocytes, DF-19 = primary fibroblasts) and tumour cells (BW-225, ZMK-1, GR-145, OH-65). Error bars represent standard deviations. Measurements were performed in duplicate and experiments were repeated two

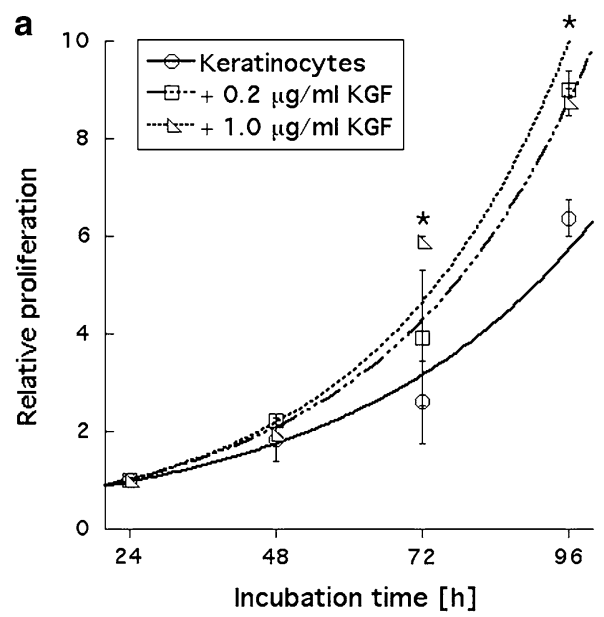

Fig. 3 a Stimulated proliferation of keratinocytes by recombinant KGF is not concentration dependent. Data were recorded over $96 \mathrm{~h}$, error bars represent \pm 1 standard deviation; statistically significant $(P \leq 0.05)$ stimulation was observed at 72 and $96 \mathrm{~h}$, as marked by asterisks. Measurements were performed in triplicate, and experiments were repeated at least three times. b KGF-induced $(0.2 \mu \mathrm{g} / \mathrm{ml}$ recombinant $\mathrm{KGF}$ ) stimulated proliferation of irradiated keratinocytes

neutralization occurred at 72 (data not shown) and $96 \mathrm{~h}$. In this experiment, unspecific IgG antibodies were added as respective controls (Fig. 3b).

To test whether tumour-cell-derived KGF would also stimulate keratinocyte proliferation, keratinocytes were plated in tumour cell supernatants containing either unspecific $\operatorname{IgG}$ antibodies or a specific anti-KGF antibody at a concentration of $2 \mu \mathrm{g} / \mathrm{ml}$ antibody, which had previously been determined to be sufficient for the neutralization of 15-25 ng KGF. Addition of the specific anti-KGF antibody led to a significantly lower proliferation of keratinocytes plated in DF 19-, ZMK-1 BW-225-, and GR-145 supernatants. For keratinocytes plated in OH-65 supernatant or KGF-free keratinocyte medium $(\mathrm{KM})$, the antibody showed no effect. Data were recorded at $24,48,72$, and $96 \mathrm{~h}$ after plating; significant reduction of

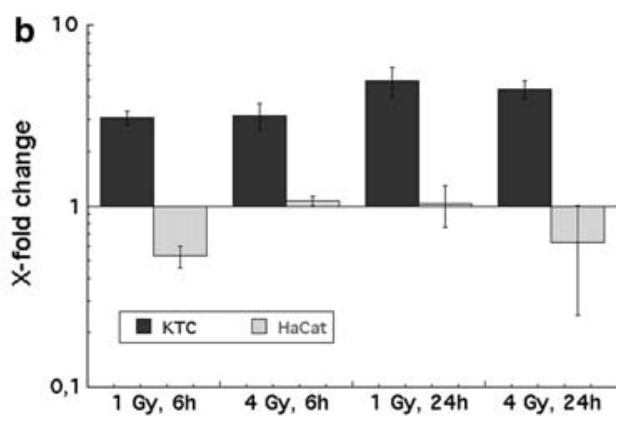

times. b Radiation-induced changes in $\mathrm{KGF}$ receptor expression in keratinocytes (KTC) and HaCat cells. Error bars represent standard deviations. Measurements were performed in duplicate, and experiments were repeated two times

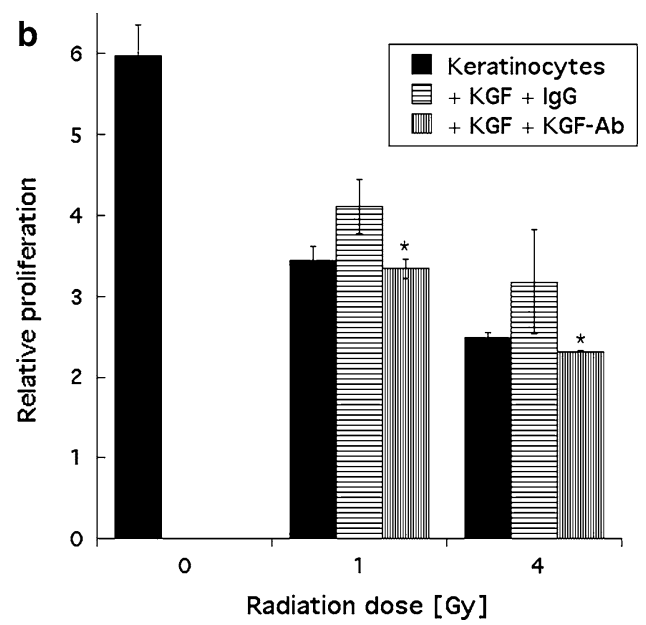

was abrogated by the addition of anti-KGF antibody to the medium. Data shown were recorded after $96 \mathrm{~h}$ of incubation. Error bars represent \pm 1 standard deviation; statistically significant $(P \leq 0.05)$ inhibition of proliferation is marked by asterisks. Measurements were performed in triplicate, and experiments were repeated at least three times

proliferation was observed at $72 \mathrm{~h}$ (data not shown) and $96 \mathrm{~h}$; Fig. $4 \mathrm{a}$ and $\mathrm{b}$ show results for cells irradiated at $1 \mathrm{~Gy}$ and 4 Gy recorded $96 \mathrm{~h}$ after plating.

Cell proliferation of tumour cells and fibroblasts in response to recombinant KGF, cell-derived KGF and additional anti-KGF antibody treatment

To test cell proliferation of tumour cells and fibroblasts in response to recombinant KGF, both cell types were incubated with $0.2 \mu \mathrm{g} / \mathrm{ml}$ recombinant KGF for 72 and $96 \mathrm{~h}$. Compared to the cell proliferation in KGF-free medium, no significant increase in proliferation was observed. Figure $5 \mathrm{a}$ shows two growth curves over $72 \mathrm{~h}$, and Fig. 5b summarizes the results recorded at $96 \mathrm{~h}$ for all cell lines tested. 


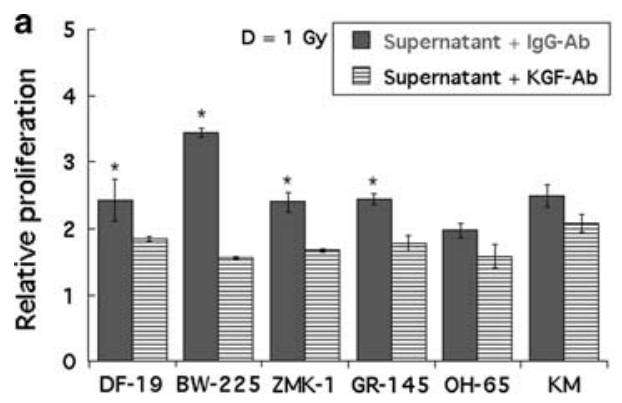

Fig. 4 a Reduced proliferation of keratinocytes in media containing a specific anti-KGF antibody compared to media containing unspecific $\mathrm{IgG}$ antibodies. Keratinocytes were plated in supernatants derived from primary fibroblasts (DF-19), epithelial tumour cells (BW-225, ZMK-1, GR-145, OH-65), or KGF-free keratinocyte medium (KM). Data were recorded for cells irradiated at $1 \mathrm{~Gy}, 96 \mathrm{~h}$ after plating. Error bars represent \pm 1 standard deviation; statistically significant $(P \leq 0.05)$ inhibition of proliferation is marked by asterisks. Measurements were performed in triplicate, and experiments were repeated at least three times. b Reduced proliferation of keratinocytes in media

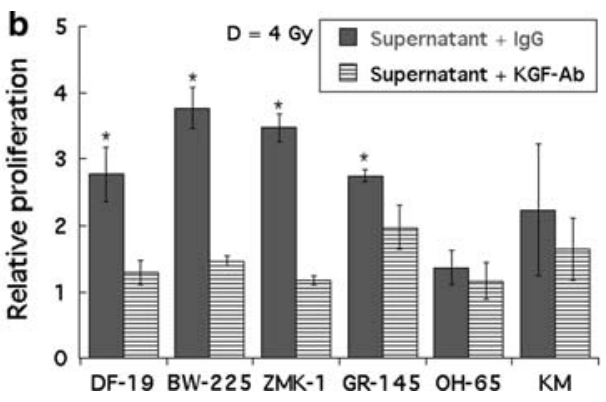

containing a specific anti-KGF antibody compared to media containing unspecific IgG antibodies. Keratinocytes were plated in supernatants derived from primary fibroblasts (DF-19), epithelial tumour cells (BW-225, ZMK-1, GR-145, OH-65), or KGF-free keratinocyte medium. Data were recorded for cells irradiated at $4 \mathrm{~Gy}, 96 \mathrm{~h}$ after plating. Error bars represent \pm 1 standard deviation; statistically significant $(P \leq 0.05)$ inhibition of proliferation is marked by asterisks. Measurements were performed in triplicate and experiments were repeated at least 3 times

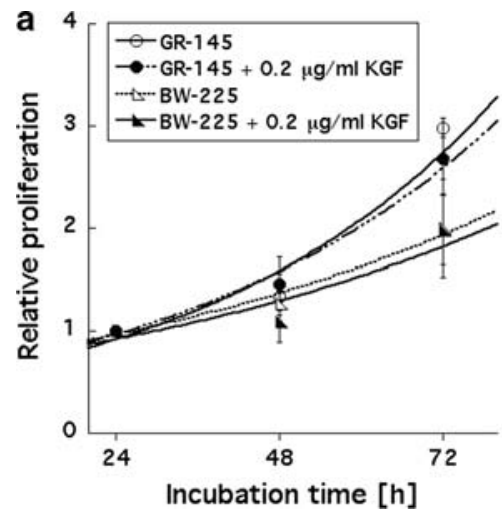

Fig. 5 a No stimulated proliferation by recombinant KGF added to tumour cell cultures for $72 \mathrm{~h}$. Open symbols represent cells plated in KGF-free medium; closed symbols represent cells plated in medium containing $0.2 \mu \mathrm{g} / \mathrm{ml}$ recombinant KGF. Data were recorded over $72 \mathrm{~h}$, error bars represent \pm 1 standard deviation. Measurements were performed in triplicate and experiments were repeated at least three times.

To test whether the addition of a neutralizing anti-KGF antibody would influence cell proliferation or radiation response, tumour cells and fibroblasts were plated in medium containing either unspecific $\operatorname{IgG}$ antibodies or a specific anti-KGF antibody at a concentration of $2 \mu \mathrm{g} / \mathrm{ml}$ antibody. Growth data were recorded over $96 \mathrm{~h}$, however, at no time point and in none of the cell lines impaired proliferation was observed for cells plated in the presence of the neutralizing antibody. Figure $6 \mathrm{a}-\mathrm{c}$ summarize the results obtained for non-irradiated cells, and for cells irradiated at 1 or $4 \mathrm{~Gy}$.

To exclude low antibody concentrations in the medium as reason for the lack of proliferation impairment, a second treatment schedule was tested. ZMK-1 cells were incubated in medium containing $1,5,10$, or $20 \mu \mathrm{g} / \mathrm{ml}$ neutralizing

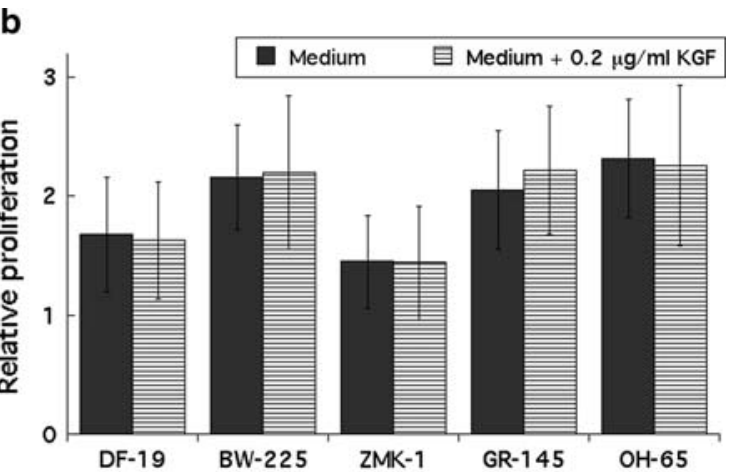

b No effect of recombinant KGF added to tumour cell cultures for $96 \mathrm{~h}$. Closed bars represent cells plated in KGF-free medium; horizontal stripes represent cells plated in medium containing $0.2 \mu \mathrm{g} / \mathrm{ml} \mathrm{recombi-}$ nant KGF. Data were recorded over $96 \mathrm{~h}$, error bars represent \pm 1 standard deviation. Measurements were performed in triplicate, and experiments were repeated at least three times

anti-KGF antibody. Compared to the proliferation in medium with an unspecific $\operatorname{IgG}$ antibody, no difference in proliferation was observed after $96 \mathrm{~h}$; additionally, no difference was seen between the various antibody concentrations (individual data not shown).

\section{Discussion}

The aim of the present study was to evaluate the role of tumour-cell-derived KGF for cell proliferation and radiation response of human epithelial tumour cells and keratinocytes. The findings are of clinical significance and important for the implementation of KGF in clinical use. In particular, we found that tumour-cell-derived KGF could 

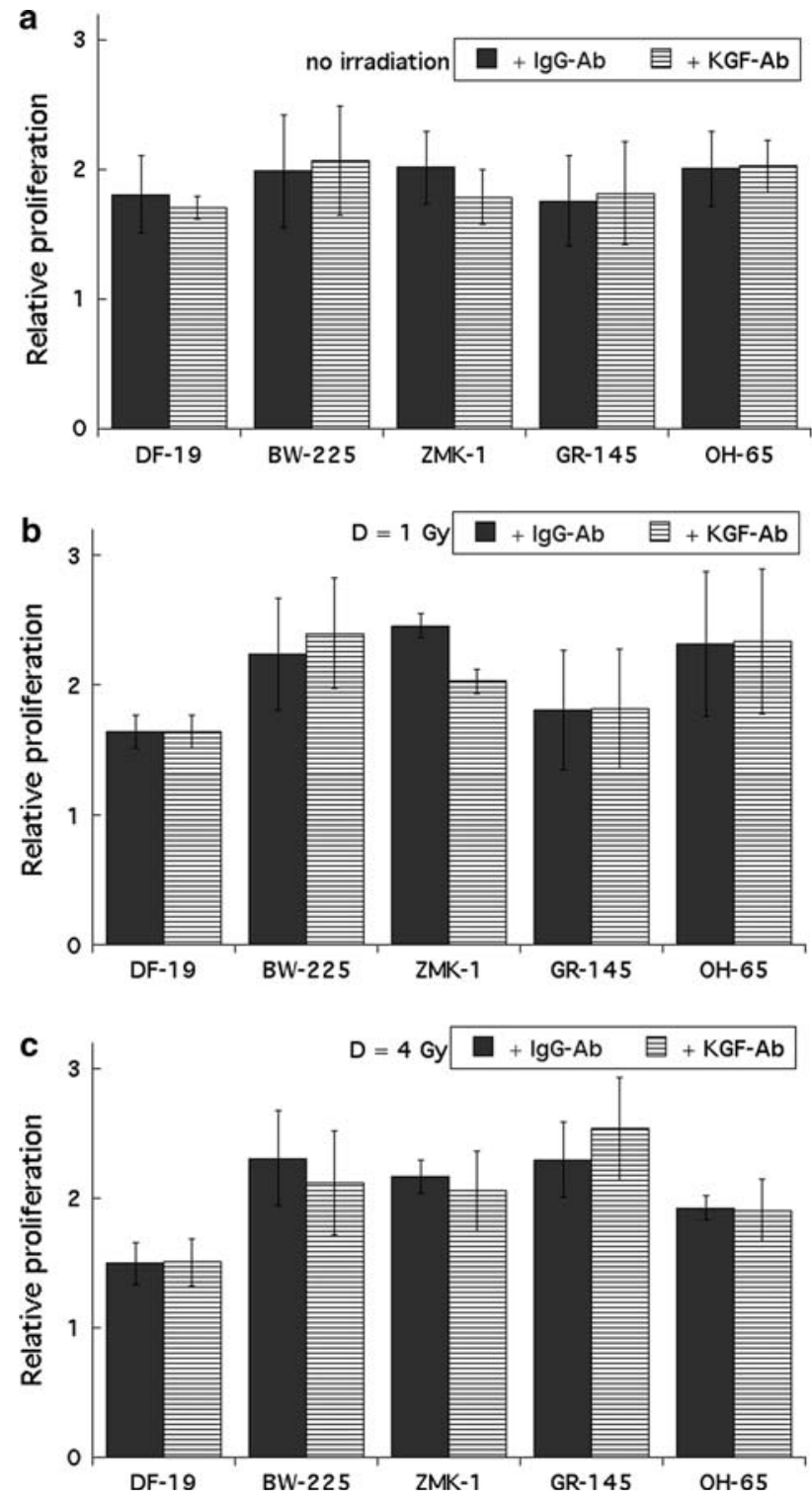

Fig. 6 a No effect of the neutralizing anti-KGF antibody on the proliferation of fibroblasts (DF-19) or epithelial tumour cells (BW-225, ZMK-1, GR-145, OH-65) was found. Data were recorded for non-irradiated cells, $96 \mathrm{~h}$ after plating. Closed bars represent cells plated in KGF-free medium; dashed bars represent cells plated in medium containing $0.2 \mu \mathrm{g} / \mathrm{ml} \mathrm{recom-}$ binant KGF. Error bars represent \pm 1 standard deviation. Measurements were performed in triplicate and experiments were repeated at least three times. $\mathbf{b}$ No effect of the neutralizing KGF antibody on the proliferation of fibroblasts (DF-19) or epithelial tumour cells (BW-225, ZMK-1, GR-145, $\mathrm{OH}-65$ ) was observed. Data were recorded for cells irradiated with $1 \mathrm{~Gy}$, $96 \mathrm{~h}$ after plating. Closed bars represent cells plated in KGF-free medium; dashed bars represent cells plated in medium containing $0.2 \mu \mathrm{g} / \mathrm{ml}$ recombinant KGF. Error bars represent \pm 1 standard deviation. Measurements were performed in triplicate and experiments were repeated at least three times. $\mathbf{c}$ No effect of the neutralizing KGF antibody on the proliferation of fibroblasts (DF-19) or epithelial tumour cells (BW-225, ZMK-1, GR-145, $\mathrm{OH}-65$ ) was found. Data were recorded for cells irradiated with $4 \mathrm{~Gy}, 96 \mathrm{~h}$ after plating. Closed bars represent cells plated in KGF-free medium; dashed bars represent cells plated in medium containing $0.2 \mu \mathrm{g} / \mathrm{ml} \mathrm{recom-}$ binant KGF. Error bars represent \pm 1 standard deviation. Measurements were performed in triplicate and experiments were repeated at least three times stimulate the proliferation of irradiated and unirradiated keratinocytes, while tumour cell proliferation was not affected. To the best of our knowledge, such experiments have not been performed before.

To demonstrate the applicability of the experimental approach, first the effect of recombinant KGF on primary keratinocytes was tested. Comparable to former results (Hille et al. 2003; Slonina et al. 2001), increased cell proliferation and altered radiation response was observed for keratinocytes treated with $\mathrm{rHuKGF}$, the pro-proliferative effect being abolished by a neutralizing anti-KGF antibody. Likewise, the secretion of a protein detectable by a KGFspecific ELISA into the culture medium of fibroblasts and epithelial tumour cells was confirmed. The presence of KGF protein in tumour cells was further supported by specific signals in Western blots. Analysis of radiation-induced changes in KGF expression showed mRNA up-regulation in fibroblasts and no systematic changes of the regulation in tumour cells. Unexpectedly, we also found KGF mRNA and protein expression in primary keratinocytes, RNA expression being up-regulated by irradiation. For confirmation, immortalized keratinocytes (HaCat cells) were tested and showed KGF mRNA expression and secretion as well.

Predominantly, KGF is produced by mesenchymal cells, and target cells are of epithelial origin. However, KGF production by normal epithelial cells has occasionally been described. One report came from Parrott et al. (2000) describing KGF expression in normal ovarian surface epithelium, which increased when cells were cultured. Another report found KGF expression in lung alveolar epithelial cells (Yamayoshi et al. 2004), and recently, Suyama et al. (2009) reported on the expression of KFG protein in epithelial cells of odontogenic keratocysts.

KGF detection is more frequent in altered epithelial cells, e.g. associated with inflammatory and tumorigenic processes. Bansal et al. (1997) described the expression of KGF mRNA in human breast cancer cell lines and purified populations of epithelial cells, Shaoul et al. (2006) found markedly increased KGF protein levels in the mucosal epithelium of patients with gastric inflammation, as well as in gastric adenocarcinoma. In the prostate, KGF expression is present in epithelial cells in benign prostate hyperplasia and prostate cancer (Planz et al. 1999). Likewise, oesophageal (Yoshino et al. 2007), pancreatic (Siddiqi et al. 1995), and colorectal (Watanabe et al. 2000) cancer samples revealed significant expression of KGF mRNA and protein, and pancreatic cancer cell lines also expressed KGF mRNA (Siddiqi et al. 1995).

$\mathrm{KGF}$ interacts only with KGF receptor and is internalized into the cytoplasm by receptor-mediated endocytosis (Belleudi et al. 2007). Therefore, in studies using immunohistochemistry, the immunolocalized KGF in the cytoplasm of epithelial cells might indicate incorporated KGF through 
KGF receptor. However, where tested, KGF expression was confirmed on the RNA level, suggesting true KGF synthesis in epithelial cells. The role of endogenous KGF in normal epithelial cells may be related to the adaptation to ex vivo culture conditions.

The expression of the KGF receptor in primary keratinocytes was expected and could be shown by Western blot and real-time PCR. Accordingly, primary keratinocytes responded to KGF application by increased proliferation. A comparable stimulation of proliferation was achieved when keratinocytes were grown in tumour cell culture supernatants. Such stimulated proliferation was also observed for irradiated cultures. Tumour cells are known to secrete growth factors other than KGF; however, two findings support the assumption that tumour-cell-derived KGF was causative for the observed stimulated proliferation of keratinocytes. First were the same results achieved with supernatant derived from fibroblast cultures, fibroblasts being a natural source of KGF. Second could the stimulated proliferation be abrogated by the application of neutralizing antiKGF antibodies. To the best of our knowledge, comparable experiments have not been reported to date.

In various preclinical and clinical studies (Beaven and Shea 2007; Brizel et al. 2008; Dorr et al. 2005a, b, c; Dorr et al. 2001; Dorr et al. 2002c; Farrell et al. 1998; Finch and Rubin 2006; Kilic et al. 2007; Lombaert et al. 2008; Meropol et al. 2003), KGF was shown to protect patients with head and neck cancer from adverse (oral mucosal) effects of radio- and/or chemotherapy, at least partly based on modification of keratinocyte proliferation and presumably differentiation. As also epithelial tumour cells express the KGF receptor, one concern with respect to the clinical use of recombinant $\mathrm{KGF}$ is that the agent not only reduces the response of normal epithelia to the treatment, but also impacts on the effect of the treatment on these epithelial tumours. Therefore, the effect of recombinant KGF on proliferation in four human epithelial tumour cell cultures was tested in the present study using the CellTiterBlue viability assay. Compared to the cell proliferation in KGF-free medium, no significant increase in proliferation was observed for tumour cells treated with recombinant KGF. Likewise, fibroblasts used as negative control culture were not responsive to treatment with recombinant KGF. These results are in accordance with the results of Ning et al. (1998) and of our former study (Hille et al. 2003). However, in the present and the former study, tumour cell cultures in very early passages were used and thus a contamination of the cultures with mesenchymal cells had been considered as well. To differentiate epithelial from mesenchymal cells, immunocytochemistry for cytokeratin (pancytokeratin and cytokeratin $4,5,6$ ) and vimentin had been applied (Hille et al. 2003). All tumour cells cultures that were used in the present study stained positive in both cyto- keratin assays. A co-expression for vimentin, as it is well known for some cultured epithelial cells, was observed in the samples as well. However, there were no cells expressing vimentin only, and hence we believe that there was no noteworthy fibroblast contamination in the tumour samples.

The mechanisms of the effects of KGF on the various cells and particularly the differences in the responses to KGF of normal and tumour cells are still not fully understood. The effect of KGF is mediated by binding to the KGF receptor, which, in normal cells, binds KGF with high affinity. A plausible explanation for the lack of KGFinduced (recombinant KGF) stimulated proliferation in the present study as well as for lacking radioprotection in the former study (Hille et al. 2003) had been the very low level of KGF receptor mRNA expression in the tumour cell cultures. We now tested whether irradiation would increase the KGF receptor expression. However, no increase in receptor mRNA expression after irradiation at 1 or 4 Gy was observed over 24 h. Others (Drugan et al. 1997; Ning et al. 1998) found no correlation between KGF cell surface receptor expression and KGF-induced proliferation.

The proliferation-enhancing effect of tumour cell supernatants on primary keratinocytes indicated the production of a biologically active protein by tumour cells. To validate that this protein was KGF, tumour cells (irradiated or not) were cultured in the presence of a neutralizing anti-KGF antibody. Within $96 \mathrm{~h}$ after irradiation and plating, there were no differences in proliferation compared to proliferation in medium with an unspecific IgG-antibody. To eliminate low antibody concentrations as reason for no effect on tumour cell growth, increased antibody concentrations were tested. However, compared to the proliferation in medium with an unspecific IgG-antibody, no difference in proliferation was observed after $96 \mathrm{~h}$, and no difference was seen between different antibody concentrations.

In conclusion, KGF expression was found in primary and immortalized keratinocytes and in tumour cell cultures established from head and neck cancer, while relevant KGFreceptor expression was only found in keratinocytes. Stimulated proliferation by either recombinant KGF or tumour-cell-derived KGF was restricted to keratinocytes. Concerning the mechanism underlying the differences in the responses to KGF of normal and tumour cells a replacement of the normal paracrine with an autocrine mechanism in case of malignant growth seems plausible. Taken together with the positive outcome of clinical studies and the amelioration of radiation tolerance of normal epithelia in animal models, these results support recombinant $\mathrm{KGF}$ as a candidate for selective amelioration of the response of normal epithelia during radiotherapy of human epithelial tumours, but also after accidental radiation exposure. 
Open Access This article is distributed under the terms of the Creative Commons Attribution Noncommercial License which permits any noncommercial use, distribution, and reproduction in any medium, provided the original author(s) and source are credited.

\section{References}

Bansal GS, Cox HC, Marsh S, Gomm JJ, Yiangou C, Luqmani Y et al (1997) Expression of keratinocyte growth factor and its receptor in human breast cancer. Br J Cancer 75(11):1567-1574

Beaven AW, Shea TC (2007) The effect of palifermin on chemotherapy and radiation therapy-induced mucositis: a review of the current literature. Support Cancer Ther 4(4):188-197

Belleudi F, Leone L, Nobili V, Raffa S, Francescangeli F, Maggio M et al (2007) Keratinocyte growth factor receptor ligands target the receptor to different intracellular pathways. Traffic 8(12):1854-1872

Boukamp P, Petrussevska RT, Breitkreutz D, Hornung J, Markham A, Fusenig NE (1988) Normal keratinization in a spontaneously immortalized aneuploid human keratinocyte cell line. J Cell Biol 106(3):761-771

Brizel DM, Murphy BA, Rosenthal DI, Pandya KJ, Gluck S, Brizel HE et al (2008) Phase II study of palifermin and concurrent chemoradiation in head and neck squamous cell carcinoma. J Clin Oncol 26(15):2489-2496

Danilenko DM (1999) Preclinical and early clinical development of keratinocyte growth factor, an epithelial-specific tissue growth factor. Toxicol Pathol 27(1):64-71

Dorr W (2003) Modulation of repopulation processes in oral mucosa: experimental results. Int J Radiat Biol 79(7):531-537

Dorr W, Noack R, Spekl K, Farrell CL (2001) Modification of oral mucositis by keratinocyte growth factor: single radiation exposure. Int J Radiat Biol 77(3):341-347

Dorr W, Hamilton CS, Boyd T, Reed B, Denham JW (2002a) Radiation-induced changes in cellularity and proliferation in human oral mucosa. Int J Radiat Oncol Biol Phys 52(4):911-917

Dorr W, Spekl K, Farrell CL (2002b) Amelioration of acute oral mucositis by keratinocyte growth factor: fractionated irradiation. Int J Radiat Oncol Biol Phys 54(1):245-251

Dorr W, Spek1 K, Farrell CL (2002c) The effect of keratinocyte growth factor on healing of manifest radiation ulcers in mouse tongue epithelium. Cell Prolif 35(Suppl 1):86-92

Dorr W, Bassler S, Reichel S, Spekl K (2005a) Reduction of radiochemotherapy-induced early oral mucositis by recombinant human keratinocyte growth factor (palifermin): experimental studies in mice. Int J Radiat Oncol Biol Phys 62(3):881-887

Dorr W, Heider K, Spekl K (2005b) Reduction of oral mucositis by palifermin (rHuKGF): dose-effect of rHuKGF. Int J Radiat Biol 81(8):557-565

Dorr W, Reichel S, Spekl K (2005c) Effects of keratinocyte growth factor (palifermin) administration protocols on oral mucositis (mouse) induced by fractionated irradiation. Radiother Oncol 75(1):99-105

Drugan CS, Stone A, Game SM, Prime SS (1997) The mitogenic effect of KGF and the expression of its cell surface receptor on cultured normal and malignant human oral keratinocytes and on contiguous fibroblasts. J Oral Pathol Med 26(7):327-333

Epstein JB, Klasser GD (2006) Emerging approaches for prophylaxis and management of oropharyngeal mucositis in cancer therapy. Expert Opin Emerg Drugs 11(2):353-373

Farrell CL, Bready JV, Rex KL, Chen JN, DiPalma CR, Whitcomb KL et al (1998) Keratinocyte growth factor protects mice from chemotherapy and radiation-induced gastrointestinal injury and mortality. Cancer Res 58(5):933-939

Farrell CL, Rex KL, Kaufman SA, Dipalma CR, Chen JN, Scully S et al (1999) Effects of keratinocyte growth factor in the squamous epithelium of the upper aerodigestive tract of normal and irradiated mice. Int J Radiat Biol 75(5):609-620

Finch PW, Rubin JS (2006) Keratinocyte growth factor expression and activity in cancer: implications for use in patients with solid tumors. J Natl Cancer Inst 98(12):812-824

Fleischer G, Dorr W (2006) Amelioration of early radiation effects in oral mucosa (mouse) by intravenous or subcutaneous administration of amifostine. Strahlenther Onkol 182(10):567-575

Hille A, Rave-Frank M, Pradier O, Damm C, Dorr W, Jackel MC et al (2003) Effect of keratinocyte growth factor on the proliferation, clonogenic capacity and colony size of human epithelial tumour cells in vitro. Int J Radiat Biol 79(2):119-128

Jaal J, Dorr W (2007) Effect of recombinant human keratinocyte growth factor (rHuKGF, Palifermin) on radiation-induced mouse urinary bladder dysfunction. Int $\mathbf{J}$ Radiat Oncol Biol Phys 69(2):528-533

Keefe DM, Schubert MM, Elting LS, Sonis ST, Epstein JB, RaberDurlacher JE et al (2007) Updated clinical practice guidelines for the prevention and treatment of mucositis. Cancer 109(5):820-831

Khan WB, Shui C, Ning S, Knox SJ (1997) Enhancement of murine intestinal stem cell survival after irradiation by keratinocyte growth factor. Radiat Res 148(3):248-253

Kilic Y, Rajewski K, Dorr W (2007) Effect of post-exposure administration of keratinocyte growth factor (Palifermin) on radiation effects in oral mucosa in mice. Radiat Environ Biophys 46(1):13-19

Lombaert IM, Brunsting JF, Wierenga PK, Kampinga HH, de Haan G, Coppes RP (2008) Keratinocyte growth factor prevents radiation damage to salivary glands by expansion of the stem/progenitor pool. Stem Cells 26(10):2595-2601

Meropol NJ, Somer RA, Gutheil J, Pelley RJ, Modiano MR, Rowinsky EK et al (2003) Randomized phase I trial of recombinant human keratinocyte growth factor plus chemotherapy: potential role as mucosal protectant. J Clin Oncol 21(8):1452-1458

Ning S, Shui C, Khan WB, Benson W, Lacey DL, Knox SJ (1998) Effects of keratinocyte growth factor on the proliferation and radiation survival of human squamous cell carcinoma cell lines in vitro and in vivo. Int J Radiat Oncol Biol Phys 40(1):177-187

Okunieff P, Li M, Liu W, Sun J, Fenton B, Zhang L et al (2001) Keratinocyte growth factors radioprotect bowel and bone marrow but not KHT sarcoma. Am J Clin Oncol 24(5):491-495

Parrott JA, Kim G, Mosher R, Skinner MK (2000) Expression and action of keratinocyte growth factor (KGF) in normal ovarian surface epithelium and ovarian cancer. Mol Cell Endocrinol 167(1-2):77-87

Planz B, Aretz HT, Wang Q, Tabatabaei S, Kirley SD, Lin CW et al (1999) Immunolocalization of the keratinocyte growth factor in benign and neoplastic human prostate and its relation to androgen receptor. Prostate 41(4):233-242

Shaoul R, Eliahu L, Sher I, Hamlet Y, Miselevich I, Goldshmidt O et al (2006) Elevated expression of FGF7 protein is common in human gastric diseases. Biochem Biophys Res Commun 350(4):825-833

Siddiqi I, Funatomi H, Kobrin MS, Friess H, Buchler MW, Korc M (1995) Increased expression of keratinocyte growth factor in human pancreatic cancer. Biochem Biophys Res Commun 215(1):309-315

Slonina D, Hoinkis C, Dorr W (2001) Effect of keratinocyte growth factor on radiation survival and colony size of human epidermal keratinocytes in vitro. Radiat Res 156(6):761-766

Spielberger R, Stiff P, Bensinger W, Gentile T, Weisdorf D, Kewalramani $T$ et al (2004) Palifermin for oral mucositis after intensive therapy for hematologic cancers. N Engl J Med 351(25):2590-2598

Suyama Y, Kubota Y, Yamashiro T, Ninomiya T, Koji T, Shirasuna K (2009) Expression of keratinocyte growth factor and its receptor in odontogenic keratocysts. J Oral Pathol Med 38(5):476-480 
Watanabe M, Ishiwata T, Nishigai K, Moriyama Y, Asano G (2000) Overexpression of keratinocyte growth factor in cancer cells and enterochromaffin cells in human colorectal cancer. Pathol Int 50(5):363-372

Yamayoshi T, Nagayasu T, Matsumoto K, Abo T, Hishikawa Y, Koji $\mathrm{T}$ (2004) Expression of keratinocyte growth factor/fibroblast growth factor- 7 and its receptor in human lung cancer: correlation with tumour proliferative activity and patient prognosis. J Pathol 204(1):110-118

Yoshino M, Ishiwata T, Watanabe M, Matsunobu T, Komine O, Ono Y et al (2007) Expression and roles of keratinocyte growth factor and its receptor in esophageal cancer cells. Int J Oncol 31(4):721-728 